Cronfa - Swansea University Open Access Repository

This is an author produced version of a paper published in :

Materials Science and Technology

Cronfa URL for this paper:

http://cronfa.swan.ac.uk/Record/cronfa5835

http://dx.doi.org/10.1179/026708309X12567268926605

This article is brought to you by Swansea University. Any person downloading material is agreeing to abide by the terms of the repository licence. Authors are personally responsible for adhering to publisher restrictions or conditions. When uploading content they are required to comply with their publisher agreement and the SHERPA RoMEO database to judge whether or not it is copyright safe to add this version of the paper to this repository. http://www.swansea.ac.uk/iss/researchsupport/cronfa-support/ 


\title{
The Role of Grain Boundaries in Creep Strain Accumulation
}

\author{
B Wilshire and MT Whittaker \\ Materials Research Centre, School of Engineering, Swansea University, Swansea. SA2 8PP
}

\begin{abstract}
To explain the seemingly-complex results obtained when creep property measurements are described using power law equations, it is commonly assumed that a transition from dislocation to diffusional creep processes occurs with decreasing applied stress. However, this assumption is negated by observations recorded for aluminium, copper and various particle-hardened alloys. Thus, all features of power law behaviour for copper are predicted by new relationships based on normalization of the stress through the yield and ultimate tensile stresses determined from high-strain-rate tests at the creep temperatures. Moreover, the particle-free zones sometimes found on grain boundaries normal to the tensile axis exist prior to creep exposure, so do not provide definitive evidence for diffusional creep mechanisms. It is therefore proposed that the dominant dislocation processes differ only in detail as the test duration and temperature increase.
\end{abstract}

Keywords: Creep mechanisms; creep data analysis; particle-free zones

\section{Introduction}

At temperatures above about $0.4 \mathrm{~T}_{\mathrm{m}}$ (where $\mathrm{T}_{\mathrm{m}}$ is the absolute melting point), the mechanisms controlling creep of pure metals have usually been identified through the dependencies of the minimum or secondary creep rate $\left(\dot{\varepsilon}_{m}\right)$ on stress $(\sigma)$, temperature $(\mathrm{T})$ and grain diameter (d) using power law equations of the form

$$
\dot{\varepsilon}_{\mathrm{m}}=A \sigma^{n}(1 / d)^{p} \exp \left(-Q_{C} / R T\right)
$$

where $\mathrm{R}=8.314 \mathrm{Jmol}^{-1} \mathrm{~K}^{-1}$. With eq. (1), the parameter (A), the stress exponent (n), the grain size exponent $(\mathrm{p})$ and the apparent activation energy for creep $\left(\mathrm{Q}_{\mathrm{C}}\right)$ are themselves functions of stress and temperature. In general, this problem of 'variable constants' has been addressed by assuming that 
different creep mechanisms govern the properties displayed in different stress/ temperature regimes. In turn, the mechanism dominant under specific test conditions is commonly decided by comparing theoretically-predicted and experimentally-determined values of $n, p$ and $\mathrm{Q}_{\mathrm{C}}$.

With polycrystalline metals, creep occurs by diffusion-controlled dislocation processes when $n \cong 4$ or more, with a decrease towards $\mathrm{n} \cong 1$ at low stresses widely attributed to a transition to diffusional mechanisms not involving dislocation movement. Diffusional creep relies on stress-directed flow of vacancies from grain boundaries under tension to those under compression. This flow may take place predominantly through the grains at $\sim 0.7 \mathrm{~T}_{\mathrm{m}}$ and above, termed Nabarro-Herring creep [1,2], and along grain boundaries as the temperature is reduced towards about $0.4 \mathrm{~T}_{\mathrm{m}}$, termed Coble creep [3].

Diffusional creep theories are elegant, giving explicit formulae to quantify the expected creep rates. Thus, with Nabarro-Herring creep, $\mathrm{n}=1, \mathrm{p}=2$ and $\mathrm{Q}_{\mathrm{C}}=\mathrm{Q}_{\mathrm{L}}$, where $\mathrm{Q}_{\mathrm{L}}$ is the activation energy for lattice diffusion. In the Coble creep range, $\mathrm{n}=1, \mathrm{p}=3$ and $\mathrm{Q}_{\mathrm{C}}=\mathrm{Q}_{\mathrm{GB}}$, where $\mathrm{Q}_{\mathrm{GB}}$ is the activation energy for grain boundary diffusion. Numerous studies have then sought to produce evidence which supports diffusional creep concepts, with the most quoted investigations probably being

(a) the $\mathrm{n}, \mathrm{p}$ and $\mathrm{Q}_{\mathrm{c}}$ values reported for polycrystalline copper [4-6] and

(b) the detection of precipitate-free zones at grain boundaries normal to low tensile stresses during

creep of particle-hardened magnesium alloys $[7,8]$.

These and other experimental observations offered as verification of diffusional creep mechanisms have been challenged $[9,10]$ and defended $[11,12]$ frequently. However, $n$ values near unity have been recorded for single crystals and coarse-grain polycrystals of pure aluminium during creep at low stresses [13-15]. With large crystal sizes, diffusional creep processes would be imperceptibly slow, so creep must be able to occur by dislocation movement in the $n \cong 1$ range. As a result, debate has continued for several decades over the importance of dislocation and diffusional creep mechanisms in the low stress regime [16], indicating that the evidence so far considered has been inconclusive. For this reason, the present study discusses the rate-controlling processes when $n \cong 1$ by reference to information now available on the tensile creep properties of aluminium, copper and various particlehardened alloys.

\section{Creep of pure aluminium}

Adopting eq. (1), numerous data sets for pure aluminium are presented in Fig.1, showing the stress dependence of $\dot{\varepsilon}_{\mathrm{m}} \exp \left(Q_{C} / R T\right)$, with $\mathrm{Q}_{\mathrm{C}}=149 \mathrm{kJmol}^{-1}$, a value close to that expected for lattice diffusion. Covering temperature-compensated $\dot{\varepsilon}_{\mathrm{m}}$ measurements spanning almost 15 orders of 
magnitude, the results obtained in different investigations are comparable when $n \cong 4$ or more at stresses above $0.5 \mathrm{MPa}$, whereas significantly different behaviour is found at lower stresses (Fig.1).

In the high stress range, constant-strain-rate tests carried out at 535 to $623 \mathrm{~K}$ for $99.99 \% \mathrm{Al}$ with uniform grain diameters of $\sim 100,165$ and $300 \mu \mathrm{m}$ produced results matching those determined at $523 \mathrm{~K}$ for the material with $\mathrm{d} \cong 100 \mu \mathrm{m}$ tested using constant-stress creep machines [17]. Again using highprecision constant-stress equipment, $\dot{\varepsilon}_{\mathrm{m}}$ values at $573 \mathrm{~K}$ are included in Fig. 1 for $99.996 \% \mathrm{Al}$ with $\mathrm{d} \cong 200 \mu \mathrm{m}$ and $\mathrm{d} \cong 2800 \mu \mathrm{m}$, as well as for single crystals [18]. All of these measurements are also consistent with constant-stress data published by Servi and Grant [19], when $n \cong 4$ or more at 477 to 866K for $99.995 \% \mathrm{Al}$ with $\mathrm{d}=100 \mu \mathrm{m}$ (Fig.1).

To illustrate the deformation characteristics at low stresses, Fig.1 contains $\dot{\varepsilon}_{\mathrm{m}}$ values at $\sim 920 \mathrm{~K}$ $\left(\sim 0.99 \mathrm{~T}_{\mathrm{m}}\right)$ for aluminium single crystals and polycrystals with $\mathrm{d} \cong 1000$ to $3000 \mu \mathrm{m}$ [13-15]. With large crystals sizes, dislocation creep must be dominant. This type of behaviour has been termed HarperDorn creep, with $\mathrm{n} \cong 1, \mathrm{p} \cong 0$, low dislocation densities within the grains and creep rates much higher than the values predicted by diffusional creep theories. However, for aluminium samples of $99.99 \%$ or higher purities with $\mathrm{d} \cong 5000 \mu \mathrm{m}$ tested at 0.94 to $0.99 \mathrm{~T}_{\mathrm{m}}$ [20], the documented $\dot{\varepsilon}_{\mathrm{m}}$ measurements were lower than those showing $\mathrm{n} \cong 1$ (Fig.1). In fact, in the low stress regime for pure aluminium, $\mathrm{n}$ values of 5 [21] and 3 [22] have been reported.

The seemingly-complex properties displayed at low stresses could be a simple consequence of the data scatter inevitable when dealing with very low creep rates. Even so, an alternative explanation can be advanced [23]. At high stresses, all results are well represented by the least-squares regression curve in Fig. 1 but, on projecting this curve into the low stress range, the gradient decreases from $n>4$ above about $20 \mathrm{MPa}$ towards $\mathrm{n} \cong 2.5$ to 3.0 at stresses less than $0.1 \mathrm{MPa}$. In the low stress regime, the projected curve lies between the $\dot{\varepsilon}_{\mathrm{m}}$ values suggesting $\mathrm{n} \cong 1$ [13-15] and those indicating that $\mathrm{n} \cong 4$ [20].

Interestingly, the data presentation in Fig.1 almost replicates observations made by Ginter, Chaudhury and Mohamed [24] for double-shear tests at 923K using coarse-grain specimens of $99.99 \%$ and 99.9995\% Al. As in Fig.1, the stress/creep rate plots in Fig.2 show that $\mathrm{n} \cong 4.5$ at high stresses, with the different $n$ values at low stresses explained in the following way[24].

(a) With $99.9995 \% \mathrm{Al}$, the Harper-Dorn condition that $\mathrm{n} \cong 1$ was linked to periodic accelerations in creep rate due to dynamic recrystallisation, giving 'averaged' $\dot{\varepsilon}_{\mathrm{m}}$ values above those measured when $\mathrm{n} \cong 2.5$ in the absence of dynamic recrystallisation.

(b) Choosing $99.99 \% \mathrm{Al}$ avoided dynamic recrystallisation and lowered the creep rates, such that $\mathrm{n} \cong 4$ even at low stresses (Fig.2). 
More recently, commercially-pure lead (99.95\%) and high-purity lead (99.999\%) having large uniform grain sizes were creep tested at around 573K [25]. However, with the $99.999 \% \mathrm{~Pb}$, periodic accelerations giving faster overall creep rates as a result of dynamic recrystallization provided $\mathrm{n}$ values of 3 rather than 1 . Once again, with the $99.95 \% \mathrm{~Pb}$, periodic accelerations in creep rate were not found, giving lower measured creep rates. On this basis, it was concluded that the linear stress dependence thought to characterize Harper-Dorn creep is probably a direct consequence of making short-term measurements involving total creep strains less than 0.01 [25].

In the high-stress range for aluminium (Fig.1), the similarity in the $\dot{\varepsilon}_{\mathrm{m}}$ values found for samples having different grain diameters has been the key observation responsible for the widely-held view that dislocation creep processes are grain-size independent, i.e. $p \cong 0$ when $n>4$. Yet, dislocation processes must also be dominant in the low stress regime, irrespective of the variations in $n$ value (Figs.1 and 2), when tests are performed at temperatures close to the melting point for single crystals and coarse grain polycrystals $(\mathrm{d}>1000 \mu \mathrm{m})$. So, to consider the stress dependences of the creep rates over ranges of temperature and grain size significantly broader than those covered for aluminium, data sets are now compared for single crystals and polycrystals of pure copper, taking advantage of the observations documented in many studies undertaken throughout the last half century.

\section{Creep data comparisons for pure copper}

With polycrystalline copper, a decrease from $\mathrm{n} \cong 5$ to $\mathrm{n} \cong 1$ with decreasing stress has been taken as evidence for a transition from dislocation to diffusional creep mechanisms [6]. Similarly a decrease from $\mathrm{Q}_{\mathrm{C}} \cong 200 \mathrm{kJmol}^{-1}$ to $\mathrm{Q}_{\mathrm{C}}<130 \mathrm{kJmol}^{-1}$ on lowering the creep temperature from above to below about $0.7 \mathrm{~T}_{\mathrm{m}}$ [4] is consistent with a change from processes controlled by lattice diffusion to mechanisms involving preferential diffusion along dislocations or grain boundaries. In addition, while $\mathrm{p} \cong 0$ at high stresses when $\mathrm{d}>100 \mu \mathrm{m}[26]$, the results in Fig. 3 indicate that $\mathrm{p}=2$ at $0.82 \mathrm{~T}_{\mathrm{m}}(1111 \mathrm{~K})$ and $\mathrm{p}=3$ at $0.61 \mathrm{~T}_{\mathrm{m}}(823 \mathrm{~K})$, as expected for a transition from Nabarro-Herring to Coble creep as the temperature is reduced in the low stress regime when $\mathrm{n} \cong 1$ [5].

These results support the view that the dominant creep process can be identified from the $\mathrm{n}, \mathrm{p}$ and $\mathrm{Q}_{\mathrm{c}}$ values found when $\dot{\varepsilon}_{\mathrm{m}}$ measurements are described using power-law equations. Indeed, constantstress tests recently carried out at 686 to $823( \pm 1) \mathrm{K}$ for $99.95 \% \mathrm{Cu}$ with $\mathrm{d} \cong 40 \mu \mathrm{m}$ have confirmed [27] the decrease from $\mathrm{n} \cong 4.5$ to $\mathrm{n} \cong 1$ so, with $\mathrm{Q}_{\mathrm{c}} \cong 110 \mathrm{kJmol}^{-1}$, the property sets in Fig. 4 could be interpreted in terms of a transition from dislocation to Coble creep with decreasing applied stress. Yet, while reasonable agreement exists over the $\mathrm{n}$ and $\mathrm{Q}_{\mathrm{c}}$ values recorded for pure copper, the exact match between theory and experiment in Fig.3 has been questioned [23,27]. 
The $\dot{\varepsilon}_{\mathrm{m}}$ values in Fig.3 were obtained [5] from tests employing multiple temperature changes from $\sim 0.88$ to $\sim 0.59 \mathrm{~T}_{\mathrm{m}}$ for samples having initial grain diameters of $\sim 20$ to $700 \mu \mathrm{m}$, with 'grain growth disregarded'. However, a planned study of the creep processes in copper at $0.62 \mathrm{~T}_{\mathrm{m}}$ and above [28] was abandoned 'because of unacceptable grain growth'. Hence, with a variability of $\pm 10 \mathrm{~K}$ in the temperature change tests [5], combined with the problem of accurate measurement of low creep strains, discounting just the lowest-rate points in Fig. 3 alters the gradient to $\mathrm{p} \cong 2.47$ at $0.61 \mathrm{~T}_{\mathrm{m}}$ and to $\mathrm{p} \cong 2.27$ at $0.82 \mathrm{~T}_{\mathrm{m}}$ [29]. With the modified plots merely indicating that $\mathrm{p}>2$ at low stresses, this observation can be considered in relation to the conclusions drawn from a survey of the creep properties reported for copper produced with different grain diameters [30].

To avoid the uncertainties associated with grain growth at high temperatures, stress/creep rate plots at 0.53 to $0.56 \mathrm{~T}_{\mathrm{m}}$ are presented in Fig. 5 for single crystals and polycrystals of copper with grain diameters of 30 to $450 \mu \mathrm{m}$ [20,30-32]. For testpieces with $\mathrm{d} \cong 30$ to $55 \mu \mathrm{m}$, a decrease from $\mathrm{n}>4$ to $\mathrm{n} \cong 1$ is again apparent on lowering the stress from over $50 \mathrm{MPa}$ to under $2 \mathrm{MPa}$, but the stress ranges covered were not sufficient to reveal equivalent changes in $\mathrm{n}$ value for the larger grain sizes. Even so, in line with data trends observed for monel and an austenitic alloy in the dislocation creep range, $n$ values of $\sim 4.3,5.3$ and 5.5 were found for copper with mean grain diameters of 30, 100 and $450 \mu \mathrm{m}$ respectively, with $\mathrm{n} \cong 6.6$ for single crystals [30]. Thus, the $\log \dot{\varepsilon}_{\mathrm{m}} / \log \sigma$ plots in Fig.5

(a) intersect at $\sigma \cong 50 \mathrm{MPa}$, giving the impression that $\mathrm{p} \cong 0$ at high stresses, but

(b) diverge as the stress is reduced, such that $\mathrm{p} \rightarrow 2$ or more, even when dislocation processes are dominant in the $n>4$ regime.

The data sets in Fig.5 therefore contradict the common assumptions that $\dot{\varepsilon}_{\mathrm{m}}$ is always grain size independent when dislocation processes are dominant at high stresses (when $n>4$ ) and that $\dot{\varepsilon}_{\mathrm{m}}$ increases rapidly with decreasing grain diameter only when diffusional creep mechanisms control lowstress behaviour (when $\mathrm{n} \cong 1$ ). So, with conflicting results obtained in grain size studies (Figs.3 and 5), alternative approaches to creep mechanism identification are now considered, beginning with inspection of full creep strain/time curves to supplement the information provided by $\dot{\varepsilon}_{\mathrm{m}}$ measurements.

\section{Variation in creep curve shape}

Under sustained tensile stresses at $\mathrm{T}>0.4 \mathrm{~T}_{\mathrm{m}}$, on monitoring the increases in creep strain $(\varepsilon)$ with time (t), most metals and alloys display normal creep curves. These curves are generally assumed to show distinct primary, secondary and tertiary stages, prior to failure after a time, $\mathrm{t}_{\mathrm{f}}$. Mechanistic studies have then focussed predominantly on the secondary or 'steady state' creep rates, usually ignoring the 
primary and tertiary stages. However, it is the primary and tertiary periods not the secondary rate which provide information relevant to creep mechanism identification, as can be illustrated by considering the creep curves recorded for aluminium and copper.

For $99.99 \% \mathrm{Al}$ at $0.61 \mathrm{~T}_{\mathrm{m}}$ [18], single crystals and polycrystals with stable grain sizes exhibit very large creep strains before necking begins and grain boundary cavities do not form to cause intergranular fracture. Under these conditions, following the initial strain on loading $\left(\varepsilon_{0}\right)$, the creep rate, $\dot{\varepsilon}$ (=d $\varepsilon / \mathrm{dt}$ ), decreases continuously with increasing time (Fig.6). The decaying creep rate appears to approach a steady value as $\varepsilon \rightarrow 0.1$ but, in constant-stress tests which avoid stress intensification as the specimen cross-sectional area decreases with increasing creep strain, $\dot{\varepsilon}$ continues to decrease very slowly towards a steady state as $\varepsilon \rightarrow 0.4$ [33].

Continuously decaying curves are also observed with copper single crystals, whereas normal curves are found with polycrystalline testpieces when cavitation leads to the tertiary acceleration and fracture [27]. With the polycrystalline copper, plotting $\dot{\varepsilon}$ as functions of normalized time $\left(\mathrm{t} / \mathrm{t}_{\mathrm{f}}\right)$ proves that a minimum rate not a steady state occurs at all stress levels (Fig.7). Defining the time to the minimum rate as $\mathrm{t}_{\mathrm{m}}$ also reveals [27] a decrease from $\mathrm{t}_{\mathrm{m}} / \mathrm{t}_{\mathrm{f}} \cong 0.4$ towards $\mathrm{t}_{\mathrm{m}} / \mathrm{t}_{\mathrm{f}}<0.05$, reflecting the gradual change from a primary-dominated to a tertiary-dominated curve shape with increasing test duration and temperature (Fig.7). These and related observations have then led to the suggestion [33] that, when power law equations are adopted, $\mathrm{n}$ value variations are due not to mechanism transitions but to the complex dependence of $\dot{\varepsilon}_{\mathrm{m}}$ on the systematic changes in creep curve shape as the test conditions are adjusted.

When normal creep curves are recorded, the $\dot{\varepsilon} /\left(\mathrm{t} / \mathrm{t}_{\mathrm{f}}\right)$ trajectories shown for copper in Fig.7 are typical of the behaviour patterns displayed by most metals and alloys. Thus,

(a) a minimum rate $\left(\dot{\varepsilon}_{\mathrm{m}}\right)$ rather than a steady state value is generally reached when the decaying primary rate is offset by the tertiary acceleration, so

(b) instead of seeking to identify 'steady state' mechanisms, emphasis should be directed to clarification of the deformation processes controlling strain accumulation and the damage phenomena which cause the creep rate to accelerate, producing the tertiary stage and fracture.

Various damage processes can initiate or contribute to the creep rate acceleration, including intergranular and transgranular crack development, neck formation and, in the case of particlehardened alloys, the progressive loss of creep strength as precipitate coarsening occurs during creep exposure. Straightforward procedures are already available to determine the relative importance of different damage mechanisms [34]. Additional information on the dominant deformation mode has then been gained [27] by analysing creep strain accumulation as functions of $\left(\sigma / \sigma_{\mathrm{Y}}\right)$ and $\left(\sigma / \sigma_{\mathrm{TS}}\right)$, where 
$\sigma_{\mathrm{Y}}$ is the yield stress and $\sigma_{\mathrm{TS}}$ is the ultimate tensile stress measured in high-strain-rate $\left(\sim 10^{-3} \mathrm{~s}^{-1}\right)$ tensile tests carried out at creep temperatures.

\section{Patterns of creep strain accumulation}

With polycrystalline copper [27], Fig.8 shows the dependence on $\left(\sigma / \sigma_{\mathrm{Y}}\right)$ of the initial strain on loading $\left(\varepsilon_{0}\right)$ and primary strain $\left(\varepsilon_{\mathrm{p}}\right)$, where $\varepsilon_{\mathrm{p}}$ is calculated by back extrapolation of the minimum creep rate line to obtain the creep strain intercept at $\mathrm{t}=0$. Thus, $\varepsilon_{0}$ and $\varepsilon_{\mathrm{p}}$ provide measures of strain accumulation, unaffected by any later influences of damage development as creep continues. Clearly, $\varepsilon_{0}$ and $\varepsilon_{\mathrm{p}}$ are low when $\sigma<\sigma_{Y}$, but increase with increasing stress when $\sigma>\sigma_{Y}$. These observations were explained by distinguishing between the contributions to the overall creep rate ( $\dot{\varepsilon}$ ) made by [35]

(a) the grain interiors and

(b) the grain boundary zones (comprising grain boundary sliding and associated deformation in adjacent grain regions).

When $\sigma<\sigma_{\mathrm{Y}}, \varepsilon_{0}$ is low because the loading strains are essentially elastic, whereas $\varepsilon_{0}$ increases because elastic and plastic components are found as $\sigma$ is raised above $\sigma_{\mathrm{Y}}$. Moreover, when $\sigma>\sigma_{\mathrm{Y}}$, the dislocation density present immediately after loading increases rapidly as the plastic component of $\varepsilon_{0}$ increases, so $\varepsilon_{\mathrm{p}}$ also increases as $\sigma$ increases when creep strain accumulation is governed largely by dislocation processes within the grain interiors. Conversely, $\varepsilon_{0}$ and $\varepsilon_{\mathrm{p}}$ are low (Fig.8) when dislocation movement within the grains becomes progressively more difficult as $\sigma$ falls below $\sigma_{\mathrm{Y}}$, so deformation occurs mainly in the grain boundary zones. The relative contribution of zone deformation to the overall creep rate then increases as the stress is lowered and the grain size is reduced, accounting for the results in Fig.5 [27,30].

On this basis, the dislocation processes controlling strain accumulation appear to differ only in detail as the dislocation distributions become more inhomogeneous as the stress is reduced from above to below $\sigma_{\mathrm{Y}}$. This proposal was then supported by the similarities in the $\dot{\varepsilon} / \mathrm{t}$ trajectories recorded [27] following stress changes in both the $\mathrm{n} \cong 4.5$ and $n \cong 1$ regimes (Fig.4). But, with deformation occurring predominantly within the grain boundary zones when $\sigma<\sigma_{\mathrm{Y}}$, no special mechanism is needed to interpret the so-called Harper-Dorn behaviour when few lattice dislocations are evident in the $\mathrm{n} \cong 1$ range. However, it is necessary to explain why the changes in the stress dependencies of $\varepsilon_{0}$ and $\varepsilon_{\mathrm{p}}$ take place at $\sigma=\sigma_{\mathrm{Y}}$ (Fig.8), whereas the transition from $\mathrm{n} \cong 4.5$ to $\mathrm{n} \cong 1$ occurs at $\sigma \cong 0.5 \sigma_{\mathrm{Y}}$ (Fig.4). 


\section{Prediction of power law behaviour}

With unanimous agreement still not reached over the deformation mechanisms governing creep of pure metals at low stresses, even after many decades of commitment to power law property descriptions, it is relevant to question their continued adoption. For this reason, new relationships for creep data analysis [27,36,37] have been based on the normalization of $\sigma$ through $\sigma_{\mathrm{Y}}$ and $\sigma_{\mathrm{TS}}$. Although $\sigma_{\mathrm{Y}}$ or $\sigma_{\mathrm{TS}}$ can be chosen, $\sigma_{\mathrm{TS}}$ is preferred. This is because $\sigma_{\mathrm{TS}}$ is the maximum stress which can be applied during tensile creep tests, so data sets can be quantified over the full stress range from $\sigma / \sigma_{\mathrm{TS}}=1$ to $\sigma / \sigma_{\mathrm{TS}}=0$. Then, on plotting the variations in creep properties as functions of $\sigma / \sigma_{\mathrm{TS}}$, it is a straightforward matter to indicate whether individual results were obtained at stresses above or below $\sigma_{\mathrm{Y}}$.

Satisfactory descriptions of the stress and temperature dependences of $\dot{\varepsilon}_{\mathrm{m}}$ and $\mathrm{t}_{\mathrm{f}}$ must make it obvious that $\dot{\varepsilon}_{\mathrm{m}} \rightarrow \infty$ and $\mathrm{t}_{\mathrm{f}} \rightarrow 0$ as $\left(\sigma / \sigma_{\mathrm{TS}}\right) \rightarrow 1$, while $\dot{\varepsilon}_{\mathrm{m}} \rightarrow 0$ and $\mathrm{t}_{\mathrm{f}} \rightarrow \infty$ when $\left(\sigma / \sigma_{\mathrm{TS}}\right) \rightarrow 0$. These requirements are met by the equations $[27,36,37]$

$$
\begin{aligned}
\left(\sigma / \sigma_{T S}\right) & =\exp \left\{-k_{1}\left[t_{f} \exp \left(-Q_{C}^{*} / R T\right)\right]^{u}\right\} \\
\text { and } \quad\left(\sigma / \sigma_{T S}\right) & =\exp \left\{-k_{2}\left[\dot{\varepsilon}_{m} \exp \left(Q_{C}^{*} / R T\right)\right]^{v}\right\}
\end{aligned}
$$

where $Q_{c}^{*}$ is determined at constant $\left(\sigma / \sigma_{\mathrm{TS}}\right)$ rather than at constant $\sigma$ as with the estimation of $\mathrm{Q}_{\mathrm{c}}$ in eq. (1). With these relationships, the values of $\mathrm{k}_{1}$ and $\mathrm{k}_{2}$, as well as $\mathrm{u}$ and $\mathrm{v}$, are easily calculated by plotting $\ln \left[\dot{\varepsilon}_{m} \exp \left(Q_{C}^{*} / R T\right)\right]$ and $\ln \left[t_{f} \exp \left(-Q_{C}^{*} / R T\right)\right]$ against $\ln \left[-\ln \left(\sigma / \sigma_{T S}\right)\right]$. In this way, using the $\dot{\varepsilon}_{\mathrm{m}}$ measurements for polycrystalline copper in Fig.4, as with $\varepsilon_{0}$ and $\varepsilon_{\mathrm{p}}$ in Fig.8, the results in Fig.9 show that the coefficients in eq. (3) differ above and below $\sigma_{\mathrm{Y}}$, i.e. with $Q_{C}^{*}=110 \mathrm{kJmol}^{-1}, \mathrm{k}_{2}=3.13$ and $\mathrm{v}=-0.224$ when $\sigma>\sigma_{\mathrm{Y}}$, whereas $\mathrm{k}_{2}=2.14$ and $\mathrm{v}=-0.13$ when $\sigma<\sigma_{\mathrm{Y}}$ [24]. Incorporating the derived values of $\mathrm{k}_{2}$ and $\mathrm{v}$ into eq. (3) then produces the sigmoidal 'master curve' in Fig.10.

The data presentations in Figs.9 and 10 reveal property trends which conflict with traditional interpretations of power law behaviour.

(a) In Fig.4, with linear extrapolation of the $\log \dot{\varepsilon}_{\mathrm{m}} / \log \sigma$ plots from the $\mathrm{n} \cong 4.5$ range into the $\mathrm{n} \cong 1$ regime, the projected creep rates appear to be slower than the measured rates, implying that 
diffusional creep mechanisms give $\dot{\varepsilon}_{\mathrm{m}}$ values faster than those expected for dislocation processes at low stresses.

(b) In contrast, on projecting the data trend from the $\sigma>\sigma_{Y}$ into the $\sigma<\sigma_{Y}$ range in Fig.9, the measured rates are actually slower than the projected rates, i.e. $\dot{\varepsilon}_{\mathrm{m}}$ falls rapidly towards zero as the contribution of the grain interiors to the overall creep rate becomes negligible when deformation is increasingly confined to the boundary zones as $\sigma$ is reduced below $\sigma_{\mathrm{Y}}$ (Fig.10).

Analysis of the $\dot{\varepsilon}_{\mathrm{m}}$ measurements for copper using eq. (3) even accounts for the detailed changes in $\mathrm{n}$ value shown in Fig.4 [27]. Thus, the sigmoidal 'master curve' in Fig.10 can be replotted as a power law expressed as

$$
\dot{\varepsilon}_{m}=A^{*}\left(\sigma / \sigma_{T S}\right)^{n} \exp \left(-Q_{C}^{*} / R T\right)
$$

where $A^{*} \neq A$. Clearly, the predicted power law curve in Fig.11 accurately captures not only the change from $\mathrm{n} \cong 4.5$ to $\mathrm{n} \cong 1$ at $\sigma \cong 0.5 \sigma_{\mathrm{Y}}$ but also the so-called 'power-law-breakdown' phenomenon when $\mathrm{n}$ increases with increasing stress in short-term tests. All features of the power-law creep characteristics of pure copper can therefore be explained without invoking a distinctive mechanism transition from dislocation to diffusional creep processes [27]. However, to assess the general applicability of this conclusion, an evaluation must be made of reports suggesting that the formation of precipitate-free zones at grain boundaries $[7,8]$ demonstrates the dominant role of diffusional creep mechanisms during creep of precipitation-hardened alloys under low applied stresses.

\section{Formation of precipitate free zones}

In the low-stress range, while the experimentally-determined creep rates for pure metals are usually faster than the values predicted by diffusional creep theories, the measured minimum rates are generally well below the theoretical values with particle-hardened alloys. Yet, with magnesiumzirconium hydride alloys [7,8], the detection of precipitate-free zones (PFZs) on boundaries approximately normal to low tensile stresses has been taken as definitive proof of the importance of diffusional creep mechanisms, but this evidence has also been questioned.

The denuded zone observations may have been made under test conditions when $n>1$, so dislocation processes not diffusional creep mechanisms would be dominant $[9,10]$. In addition, for a Mg- $0.55 \mathrm{wt} . \%$ $\mathrm{Zr}$ alloy [28], immediately after formation of zirconium hydride particles by annealing in hydrogen, 
PFZs were present on boundaries normal to the extrusion direction, i.e. prior to creep exposure, denuded zones existed on boundaries normal to the specimen gauge length and therefore the applied tensile stress. These pre-existing zones had widths up to $\sim 1.8 \mu \mathrm{m}$ [28], comparable with the values reported after creep [7,8]. The formation of PFZs during fabrication and heat-treatment cannot be a consequence of diffusional creep processes, while any width increase during subsequent creep cannot be attributed unambiguously to diffusional mechanisms.

Controversy over the relevance of PFZs has continued recently. Thus, PFZs were reported [38] to form during creep of a commercial aluminium alloy, 7075, having a nominal composition (wt \%) of Al-5.6Zn-2.5Mg-1.6Cu-0.23Cr. For this alloy, several data sets were grouped within very broad scatter bands to suggest a sudden decrease from $n=5$ to $n=1$ on lowering the stress from above to below 5MPa at 623 to $683 \mathrm{~K}$. The detection of PFZs was again taken as confirmation that diffusional creep mechanisms were dominant in the low-stress regime [38]. However,

(a) denuded zones have been observed in the dislocation creep range when $\mathrm{n} \cong 9$ for 7075 [39] and

(b) pre-existing PFZs were certainly detectable [36] in an alloy similar in composition and microstructure to 7075, namely, 7010 having a nominal composition (wt \%) of Al-6.2Zn-2.35Mg$1.7 \mathrm{Cu}-0.1 \mathrm{Zr}$.

With 7010, PFZs were present directly after fabrication and heat treatment [36]. The average zone widths then increased from $\sim 70 \mathrm{~nm}$ before creep (Fig.12a) towards 0.1 to $0.3 \mu \mathrm{m}$ after creep at $473 \mathrm{~K}$ (Fig.12b), accompanied by appreciable coarsening of the $\eta^{\prime}$ and $\eta$ precipitates within the grains. In fact, rather than supporting diffusional creep mechanisms, inspection of Fig.12b indicates that preexisting denuded zones offer preferential locations for easy dislocation movement when $n>1$, Moreover, as with 7010, pre-existing PFZs have also been observed to increase in width when dislocation processes are dominant $(n>4)$ during creep of other precipitation-hardened aluminium alloys, including 2124 and 8090 [40].

Although PFZs have been found with certain aluminium and magnesium alloys [7,8,38], many different particle-strengthened alloys are used in high-temperature service applications involving longterm exposure under low stresses when diffusional creep mechanisms could be expected to be dominant, but PFZs are rarely seen. It therefore appears that the detection of PFZs do not provide unassailable proof of the occurrence of diffusional creep mechanisms. Indeed, results obtained by using eqs. (2) and (3) to analyse $\dot{\varepsilon}_{\mathrm{m}}$ and $\mathrm{t}_{\mathrm{f}}$ data for several commercial aluminium alloys [40] offers further support for the conclusion that diffusion-controlled dislocation processes govern creep strain accumulation at high and low stresses. 


\section{Prediction of long term creep data}

Compounding the debate over interpretation of the $\mathrm{n}, \mathrm{p}$ and $\mathrm{Q}_{\mathrm{c}}$ values recorded when power law equations are used to describe the creep properties of pure metals, no agreed explanation has yet been provided for the frequent observation that $n \gg 4$ and $Q_{c} \gg Q_{L}$ for particle-strengthened alloys at high stresses [41]. For example, with several precipitation-hardened aluminium alloys in tests lasting no more than a few thousand hours $[36,40], \mathrm{Q}_{\mathrm{c}}$ ranges from $\sim 140$ to over $200 \mathrm{kJmol}^{-1}$ at 373 to $463 \mathrm{~K}$, while the stress exponent decreases from $n>20$ to $n \cong 4$, a trend expected to continue towards $n \cong 1$ as the test duration and temperature increase.

The unpredictable variations in $\mathrm{n}$ and $\mathrm{Q}_{\mathrm{c}}$ introduce not only theoretical but also practical problems. For many high-temperature applications, design decisions are often based on the tensile stresses which the relevant alloys can sustain at the service temperatures without creep failure occurring within $100,000 \mathrm{~h}$. To obtain this long-term data, stress rupture rather than more expensive creep tests are generally employed, so only the creep fracture properties are determined. Unfortunately, power law equations, as well as the many parametric, numerical and computational methods currently adopted [42], do not allow reliable estimation of long-term strengths by extrapolation of short-term results. For this reason, protracted and expensive test programmes must now be completed to obtain the necessary design data. In contrast, eqs. (2) and (3) appear to permit accurate long-term property prediction [27,36,37].

Of the aluminium alloys for which high-precision short-term results were produced [40], the 100,000h creep rupture strengths needed to assess the predictive capabilities of eq. (2) were available only for 2124 [43]. Yet, the sigmoidal 'master curve' computed by applying eq. (2) to $t_{\mathrm{f}}$ measurements from tests lasting no more than $1000 \mathrm{~h}$ precisely defines [40] the 100,000h properties of 2124 (Fig.13). Similarly, multi-batch $100,000 \mathrm{~h}$ rupture strengths have been predicted accurately by analysis of test data lasting up to 5000h for a series of ferritic [44], bainitic [45] and martensitic steels [37] for power and petrochemical plant. Validation of this new methodology for other high-temperature alloys would therefore reduce the 'materials development cycle' from the 12 to 15 years presently required to characterise the creep design properties of new and/or improved structural materials [46].

With most metals and alloys, the product $\left(\dot{\varepsilon}_{\mathrm{m}} \cdot \mathrm{t}_{\mathrm{f}}\right)$ usually decreases slightly as the stress is reduced and the temperature is raised. Even so, $\mathrm{t}_{\mathrm{f}}$ increases systematically as $\dot{\varepsilon}_{\mathrm{m}}$ decreases, emphasising that creep fracture is strain controlled. Consequently, information on the deformation mechanisms can be inferred from the stress rupture behaviour. Thus, included in Fig.13 are the sigmoidal 'master curves' constructed [40] by applying eq. (2) to long-term $t_{f}$ measurements for two other commercial aluminium alloys, namely 2219 and 7075 [43]. By demonstrating that eq. (2) facilitates data comparisons for different alloys by covering stress ranges from $\left(\sigma / \sigma_{\mathrm{TS}}\right) \rightarrow 1$ to $\left(\sigma / \sigma_{\mathrm{TS}}\right) \rightarrow 0$, several features of the results in Fig.13 are noteworthy. 
(a) The large and variable $Q_{c}$ values found using eq. (1) are replaced by physically-meaningful $Q_{C}^{*}$ values, with $Q_{C}^{*} \cong 145 \mathrm{kJmol}^{-1}$, the value expected for diffusion-controlled dislocation movement in the aluminium alloy matrices.

(b) For temperature-compensated creep lives of $10^{-8} \mathrm{~s}^{-1}$, the $\left(\sigma / \sigma_{\mathrm{TS}}\right)$ level decreases in the order 2219, 2124 and 7075, i.e. in the order in which a loss of creep strength occurs due to precipitate coarsening during creep exposure $[36,40]$.

Finally, it should be recognised that, if different processes control the $\dot{\varepsilon}_{\mathrm{m}}$ properties (and therefore the creep lives) in different stress/temperature regimes, analysis of short-term results would not allow accurate prediction of long-term data. The fact that eq. (2) does allow extended extrapolation (Fig.13) therefore supports the view that no distinctive transition from dislocation to diffusional creep mechanisms occurs with decreasing applied stress.

\section{Conclusions}

1. For almost half a century, the creep properties of metals and alloys have usually been described using power law equations but, to account for the observed behaviour patterns, it is widely assumed that dislocation processes are dominant at high stresses, with a transition to diffusional creep mechanisms at low stresses. However, detailed inspection of normal creep strain/time curves shows that a minimum creep rate $\left(\dot{\varepsilon}_{\mathrm{m}}\right)$ not a steady-state value is commonly reached when the decaying primary rate is offset by the tertiary acceleration. Rather than seeking to identify 'steady state' mechanisms, emphasis should therefore be directed to the deformation processes governing strain accumulation and the various damage mechanisms causing the creep rate to accelerate, leading to eventual fracture.

2. The dominant deformation mode is clarified by analysing creep strain accumulation as functions of $\left(\sigma / \sigma_{\mathrm{Y}}\right)$ and $\left(\sigma / \sigma_{\mathrm{TS}}\right)$, where $\sigma_{\mathrm{Y}}$ and $\sigma_{\mathrm{TS}}$ are the yield stress and ultimate tensile strength respectively, as measured at each creep temperature. Adopting this approach, the creep and creep fracture properties are well described as

$$
\begin{aligned}
\left(\sigma / \sigma_{T S}\right) & =\exp \left\{-k_{1}\left[t_{f} \exp \left(-Q_{C}^{*} / R T\right)\right]^{u}\right\} \\
\text { and } \quad\left(\sigma / \sigma_{T S}\right) & =\exp \left\{-k_{2}\left[\dot{\varepsilon}_{m} \exp \left(Q_{C}^{*} / R T\right)\right]^{\nu}\right\}
\end{aligned}
$$


where $Q_{C}^{*}$ is determined at constant $\left(\sigma / \sigma_{\mathrm{TS}}\right)$. In this way, results at different creep temperatures are superimposed onto sigmoidal 'master curves', satisfying the requirement that $\dot{\varepsilon}_{\mathrm{m}} \rightarrow \infty$ and $\mathrm{t}_{\mathrm{f}} \rightarrow 0$ as $\left(\sigma / \sigma_{\mathrm{TS}}\right) \rightarrow 1$, while $\dot{\varepsilon}_{\mathrm{m}} \rightarrow 0$ and $\mathrm{t}_{\mathrm{f}} \rightarrow \infty$ when $\left(\sigma / \sigma_{\mathrm{TS}}\right) \rightarrow 0$.

3. These new relationships predict all features of the power-law behaviour reported for pure copper, demonstrating that the dislocation processes governing strain accumulation differ only in detail above and below $\sigma_{\mathrm{Y}}$. The results are then explained in terms of the contributions made by the grain interiors and the grain boundary zones to the overall creep rate, with $\dot{\varepsilon}_{\mathrm{m}}$ decreasing rapidly towards zero when deformation in increasingly confined to the boundary zones as $\sigma$ decreases below $\sigma_{\mathrm{Y}}$.

4. With precipitation-hardened aluminium alloys, the new relationships rationalize the complex stress and temperature dependencies of $\dot{\varepsilon}_{\mathrm{m}}$ found using power law equations, with $Q_{C}^{*} \cong 145 \mathrm{kJmol}^{-1}$, the activation energy for lattice diffusion in the alloy matrices. Moreover, the observation that particlefree zones are sometimes seen on grain boundaries normal to the applied tensile stresses does not provide unambiguous proof of the importance of diffusional creep mechanisms in the low-stress regime. Instead, these zones exist prior to creep exposure, with their width increasing with increasing test duration and temperature by offering preferred locations for dislocation movement.

5. In contrast to power law equations and other widely-adopted methods, the new relationships allow prediction of long-term properties by analysis of short-term $\dot{\varepsilon}_{\mathrm{m}}$ and $\mathrm{t}_{\mathrm{f}}$ measurements. Thus, with the aluminium alloy, 2124, the 100,000h creep rupture strengths are estimated accurately by extrapolation of $t_{f}$ values from tests lasting up to only 1000h. Clearly, if distinctly different mechanisms are dominant in different stress/temperature regimes, extended extrapolation would not be possible. Hence, the accuracy of the predictions made for 2124 and numerous other alloys supports the conclusion that no transition from dislocation to diffusional creep processes occurs with decreasing applied stress.

\section{Acknowledgements}

The financial support provided by the Welsh Assembly Government for one of the authors (BW) is gratefully acknowledged. 


\section{References}

1. Nabarro FRN. In: Report on conf. on strength of solids, 75, London:Phys Soc, 1948.

2. Herring C. J Appl Phys 1950; 21:437

3. Coble C. J Appl Phys 1963; 34:1679

4. Feltham P, Meakin JD. Acta Metall 1959; 7:614

5. Burton B, Greenwood GW. Acta Metall 1970; 18:1237

6. Burton B, Greenwood GW. Metal Sci J 1970, 4:215

7. Squires RL, Weiner RT, Phillips M. J Nucl Mater 1963; 8:77

8. Harris JE, Jones RB. J Nucl Mater 1963; 10:360

9. Wolfenstine J, Ruano OA, Wadsworth J, Sherby OD. Scripta Metall Mater 1993; 29:515

10. Ruano OA, Sherby OD, Wadsworth J, Wolfenstein J. Mater Sci Eng 1996; A211:66

11. Greenwood GW. Scripta Metall Mater 1994; 30:1527

12. Burton B, Reynolds GL. Mater Sci Eng 1995; A191: 135

13. Harper J, Dorn JE. Acta Metall 1957; 5:654

14. Barrett CR, Muehléisen EC, Nix WD. Mater Sci Eng 1972; 10:33

15. Ardell AJ, Lee SS. Acta Metall 1986; 34:2411

16. Mishra RS, Mukherjee AK, Murty KL (editors).In:Creep behaviour of advanced materials for the $21^{\text {st }}$ century. 391. Warrendale, PA, TMS;1999.

17. Davies PW, Stevens RN, Wilshire B. J Inst Metals 1966; 94:49

18. Parker JD, Wilshire B. Philos Mag 1980; 41:665

19. Servi IS, Grant NJ. Trans AIME 1951; 191:909

20. McNee KR, Greenwood GW, Jones H. Scripta Mater 2001; 44:351

21. Blum W, Maier W. Phys Stat Sol (a) 1999; 171:467

22. Kumar P, Kassner ME. Scripta Mater 2009; 60:60

23. Wilshire B, Palmer CJ. In: 'Creep deformation: Fundamentals and applications'. Mishra RS, Earthman JC, Raj SV. editors, 51.Warrendale, PA, TMS, 2002.

24. Ginter TJ, Chaudhury PK, Mohamed FA. Acta Mater 2001; 49:263

25. Cheng YC, Chauhan M, Mohamed FA. Metall Mater Trans A 2009; 40A:80

26. Barrett CR, Lytton JL, Sherby OD. Trans AIME 1967; 239:170

27. Wilshire B, Battenbough AJ. Mater Sci Eng A 2007; 443A:156

28. Aigeltinger EH, Gifkins RC. J Mater Sci 1975; 10:1889 
29. Wilshire B. In: 'Creep behaviour of advanced materials for the $21^{\text {st }}$ century'. Mishra RS, Mukerjee AK, Murty KL. editors, 451. Warrendale, PA, TMS;1999

30. Wilshire B, Palmer CJ. Scripta Mater 2002; 46:483

31. Pahutova M, Cadek J, Rys P. Philos Mag 1971; 46:483

32. Evans RW, Wilshire B. Introduction to creep. London. Inst Materials. 1993.

33. Evans RW, Wilshire B. Creep of Metals and Alloys. London. The Institute of Metals. 1985.

34. Wilshire B, Burt H. Z Metallk 2005; 96:552

35. Davies PW, Richards JD, Wilshire B. J Inst Metals 1961-62; 90:431

36. Burt H, Wilshire B. Metall Mater Trans A 2006; 37A:1005

37. Wilshire B, Scharning PJ. Inter Mater Rev 2008; 53:91

38. Srivastava V, Williams PJ, McNee KR, Greenwood GW, Jones H. Mater Sci Eng A 2004; A382:50

39. Park JG, Lee DY, Choi J. J Mater Sci 1996; 31:2719

40. Wilshire B, Scharning PJ. J Mater Sci 2008; 43:3992

41. Arzt E. Res Mech 1991; 31:399

42. Holdsworth SR, In: 'Creep and fracture of high temperature components - design and life assessment issues' Shibli IA, Holdsworth SR, Merckling G. editors, 380, London, DES tech Publ 2005.

43. Kaufman JG. 'Properties of aluminium alloys' Materials Park. Ohio. ASM. 1999.

44. Wilshire B, Scharning PJ. Int J Press Vessels and Piping 2008; 85:739

45. Wilshire B, Scharning PJ. Mater Sci Tech 2008; 24:1

46. Allen D, Garwood S. Energy Materials - strategic research agenda. Materials Energy Review. 2007. 


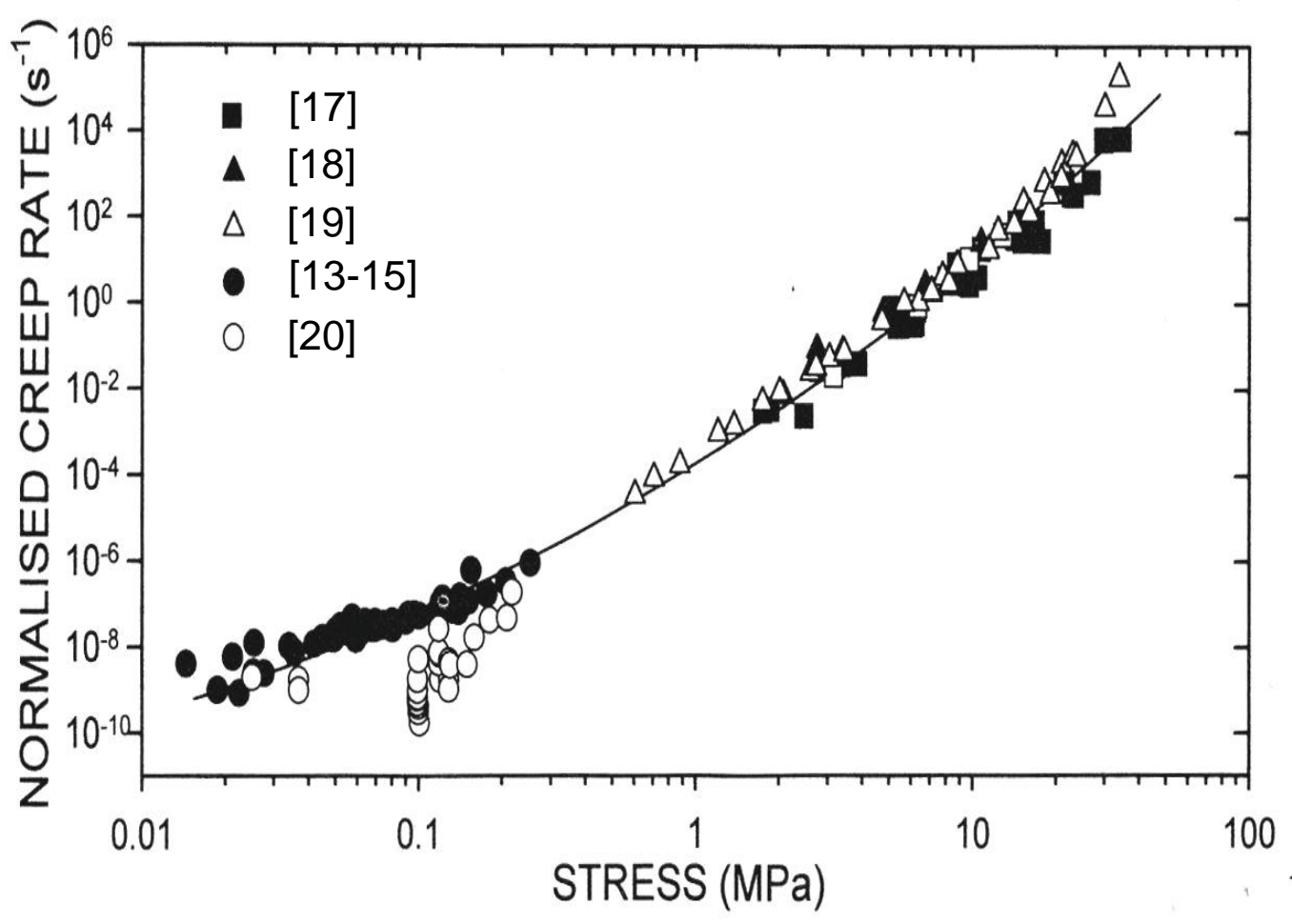

Figure 1. The stress dependence of the temperature-compensated minimum creep rates reported for single crystals and polycrystalline samples of pure aluminium [13-15,17-20], normalized to $920 \mathrm{~K}$ with $\mathrm{Q}_{\mathrm{c}}=149 \mathrm{kJmol}^{-1}[23]$.

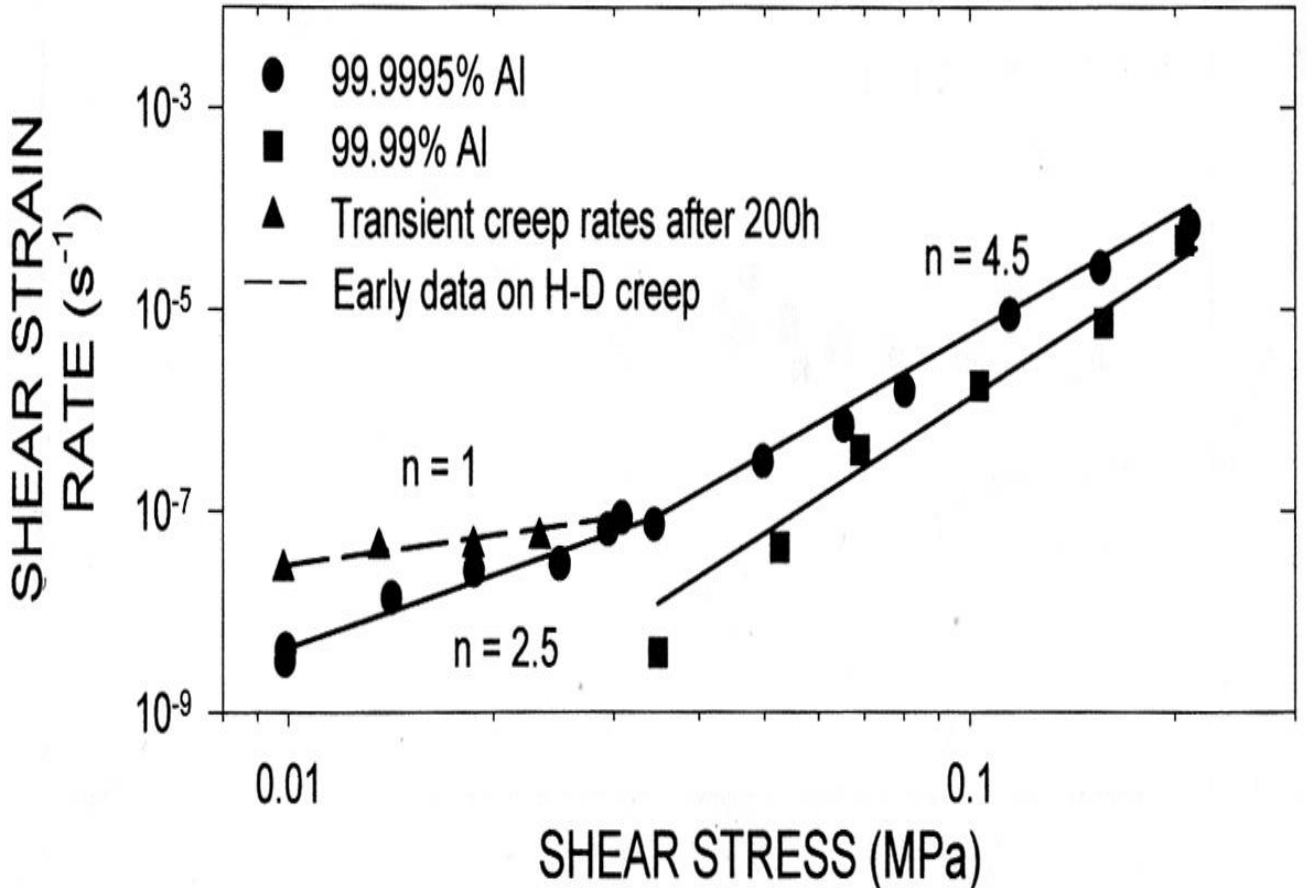

Figure 2. Shear stress/shear strain rate plots recorded in double-shear tests for coarse-grain samples of 99.99\% and $99.9995 \% \mathrm{Al}[24]$. 


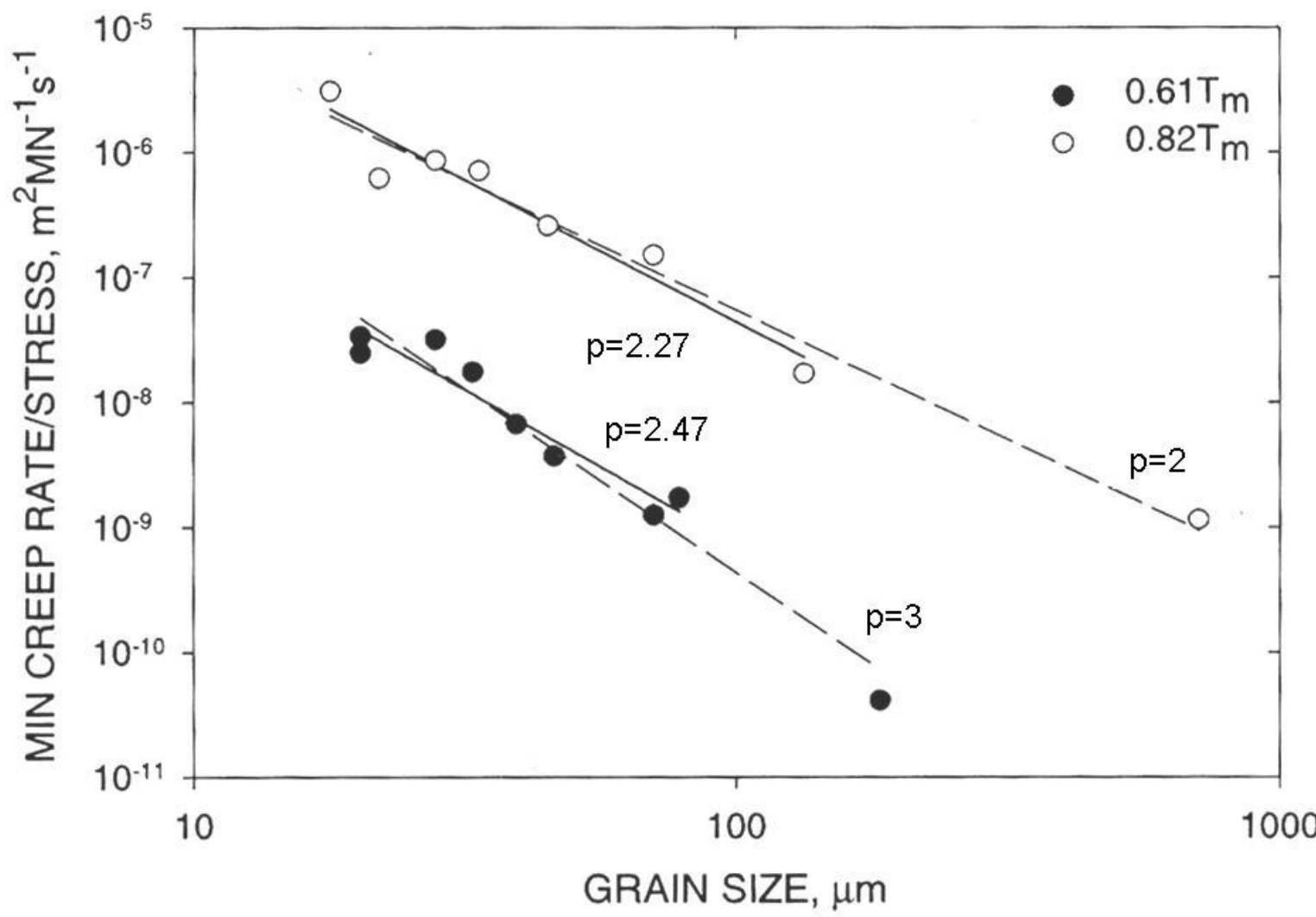

Figure 3. The grain size dependencies of the creep rates reported for pure copper in the $n \cong 1$ regime. The full data sets show $\mathrm{p}=3$ at $0.61 \mathrm{~T}_{\mathrm{m}}$ and $\mathrm{p}=2$ at $0.82 \mathrm{~T}_{\mathrm{m}}$ [5] but, after discounting the lowest rate point at each temperature, least squares analysis of the remaining results give $p=2.47$ and $p=2.27$ at $0.61 \mathrm{~T}_{\mathrm{m}}$ and $0.82 \mathrm{~T}_{\mathrm{m}}$ respectively [29]. 


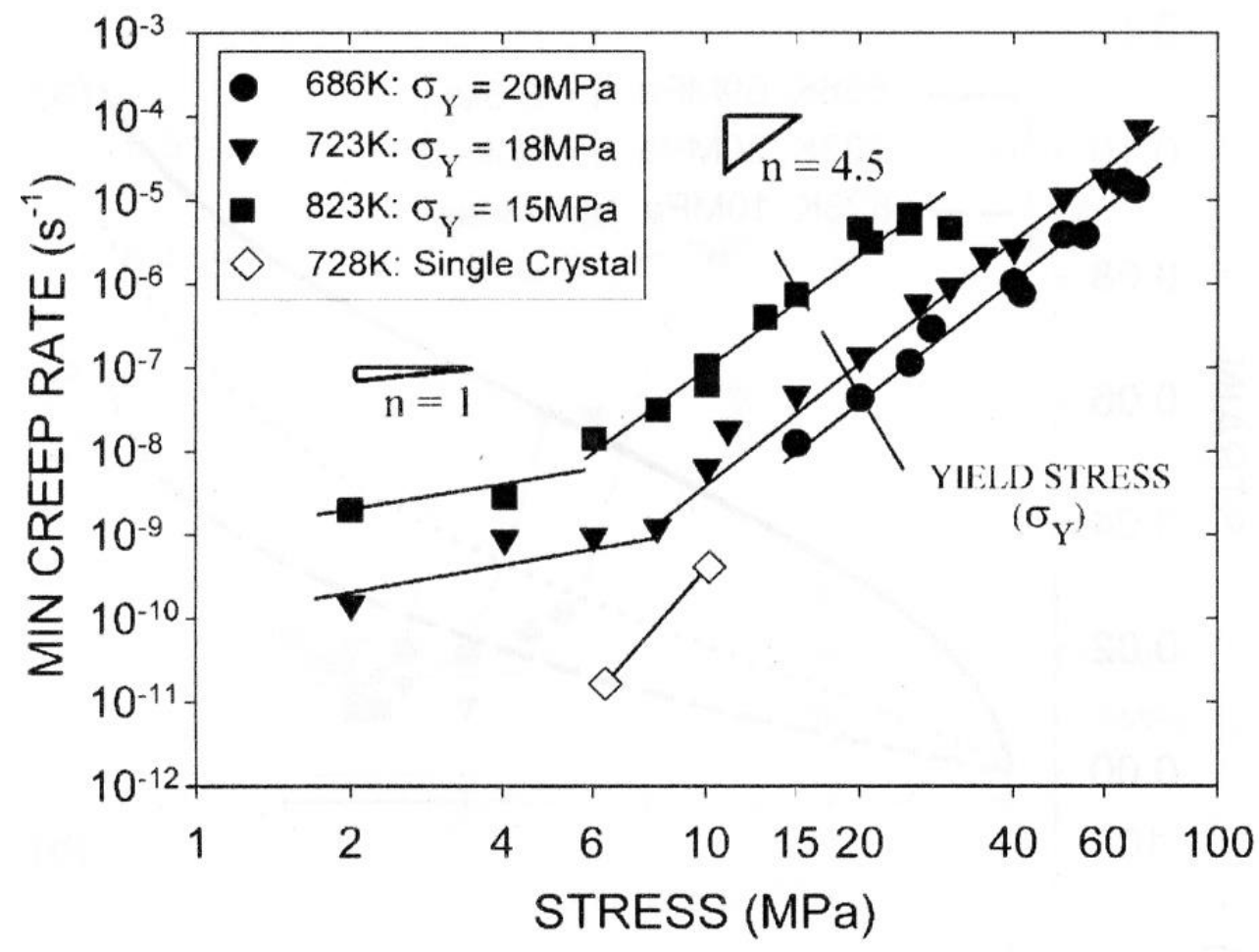

Figure 4. The stress dependencies of the minimum creep rate at 686 to $823 \mathrm{~K}$ for polycrystalline copper (with $\mathrm{d} \cong 40 \mu \mathrm{m}$ ), also showing the rates observed for copper single crystals at $728 \mathrm{~K}$ [27].

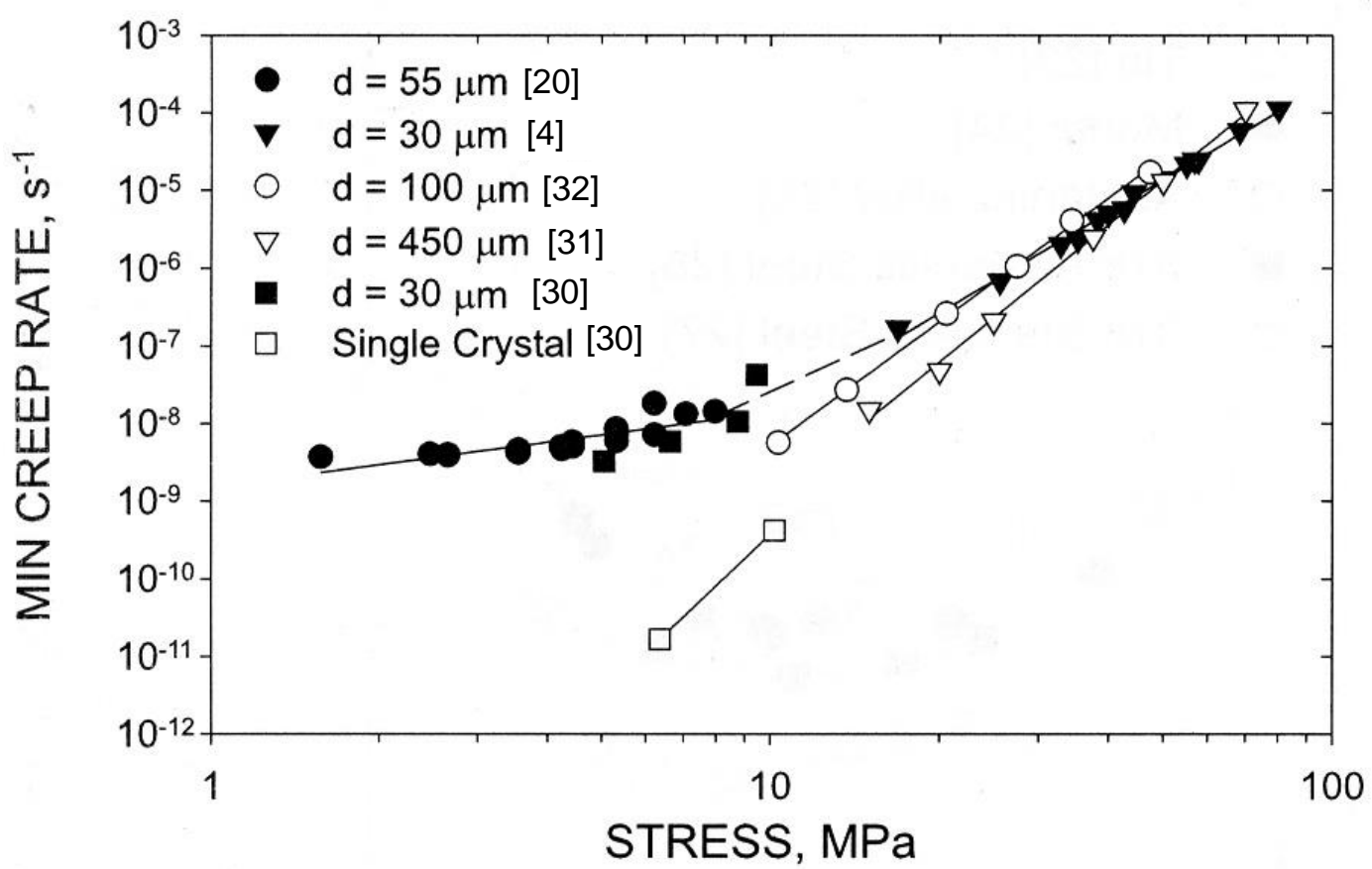

Figure 5. Stress/minimum creep rate relationships at 723 to $753 \mathrm{~K}$ for polycrystalline copper produced with grain diameters of 30 to $450 \mu \mathrm{m}$ [4,20,30-32], together with data for copper single crystals at $728 \mathrm{~K}[30]$. 


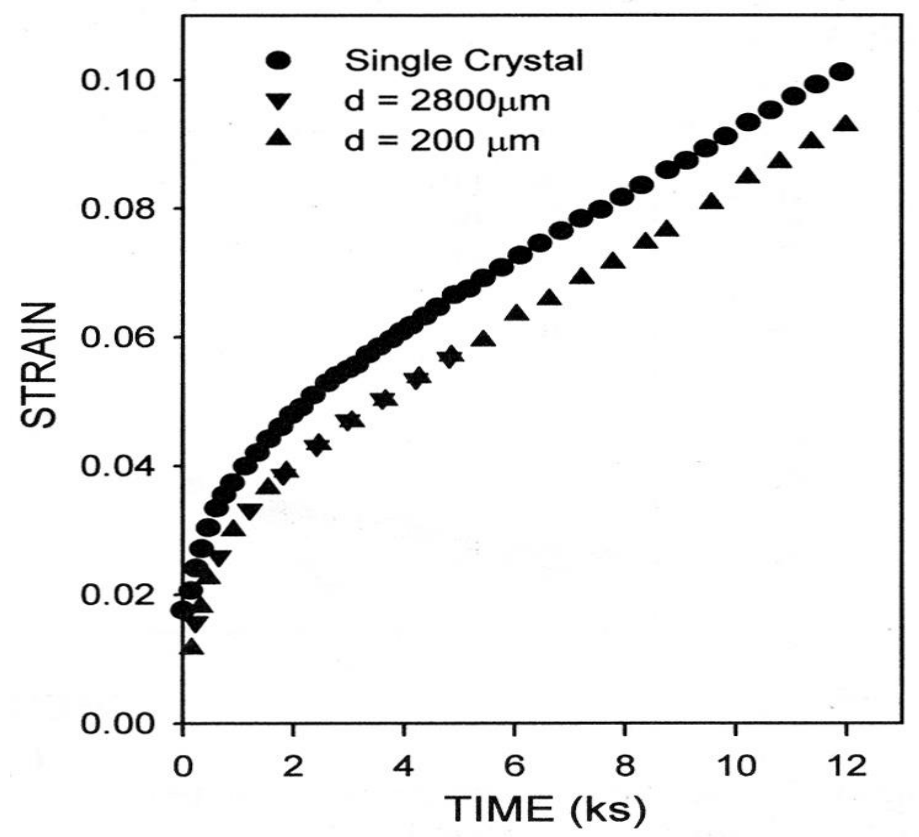

Figure 6. Creep strain/time curves for constant-stress creep tests carried out at $6.3 \mathrm{MPa}$ and $573 \mathrm{~K}$ for single crystals and polycrystalline samples of pure aluminium with grain diameters of 200 and $2800 \mu \mathrm{m}[18]$.

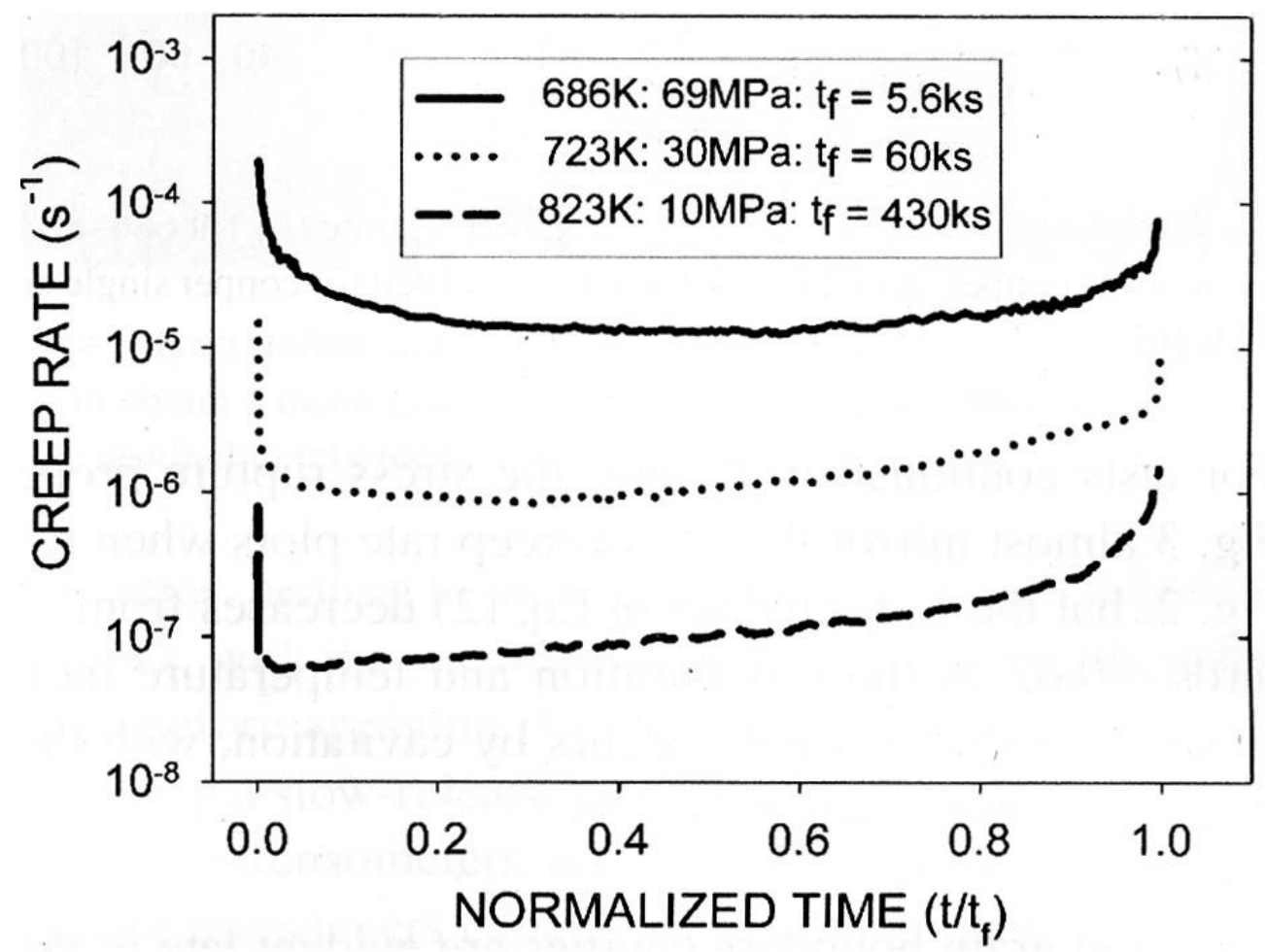

Figure 7 . The variations in the creep strain rate $(\dot{\varepsilon})$ with normalized time $\left(\mathrm{t} / \mathrm{t}_{\mathrm{f}}\right)$ observed in constant-stress tests carried out for polycrystalline copper (with $\mathrm{d} \cong 40 \mu \mathrm{m}$ ) under different stress/temperature conditions [27]. 


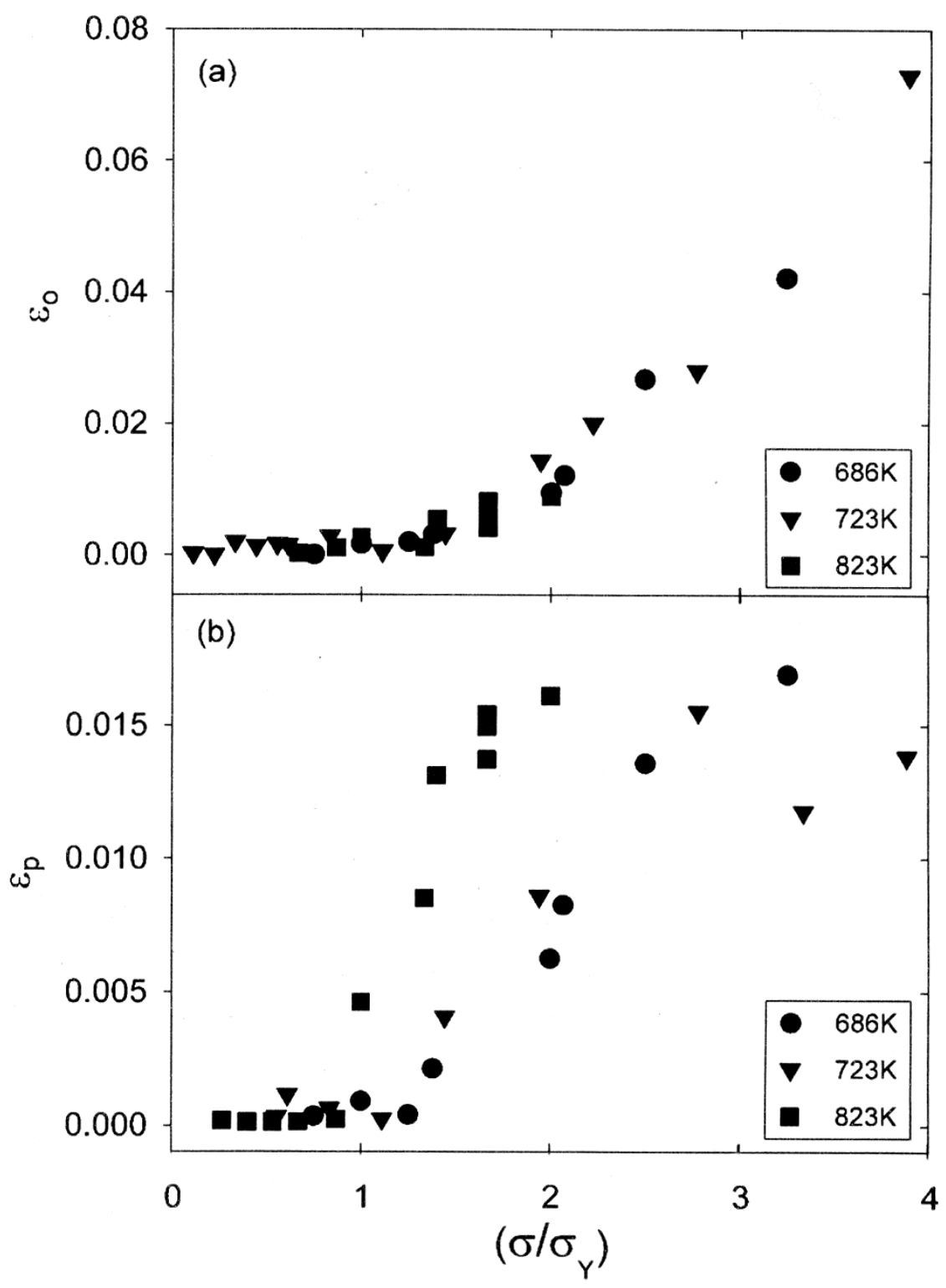

Figure 8 . The dependencies of (a) the initial strain on loading $\left(\varepsilon_{0}\right)$ and (b) the total primary strain $\left(\varepsilon_{\mathrm{p}}\right)$ on the normalized stress $\left(\sigma / \sigma_{\mathrm{Y}}\right)$ for polycrystalline copper (with $\left.\mathrm{d} \cong 40 \mu \mathrm{m}\right)$ at 686 to $823 \mathrm{~K}$ [27]. 


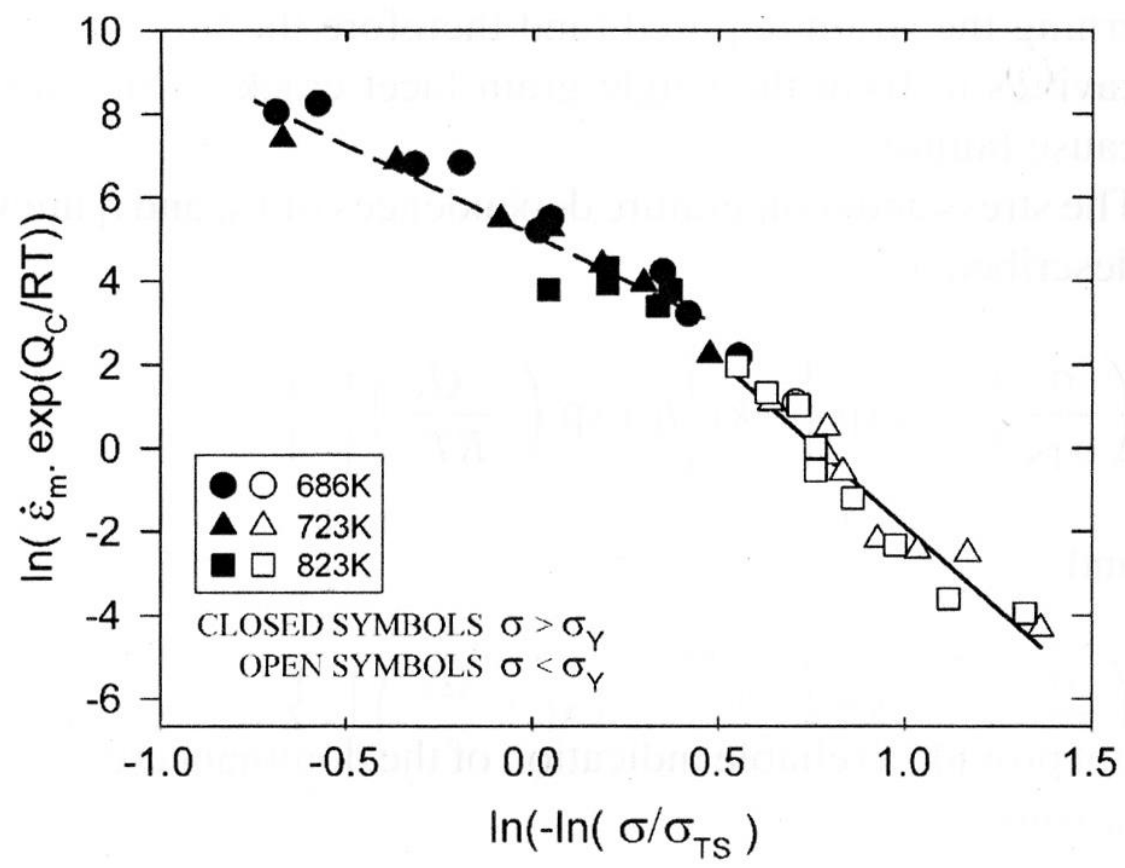

Figure 9. Determination of the coefficients in eq. (3) by plotting $\ln \left[\dot{\varepsilon}_{m} \exp (110,000 / R T)\right]$ as a function of $\ln \left[-\ln \left(\sigma / \sigma_{T S}\right)\right]$ for polycrystalline copper (with $\mathrm{d} \cong 40 \mu \mathrm{m}$ ) tested at 686 to $823 \mathrm{~K}$ under stresses above and below $\sigma_{\mathrm{Y}}[27]$.

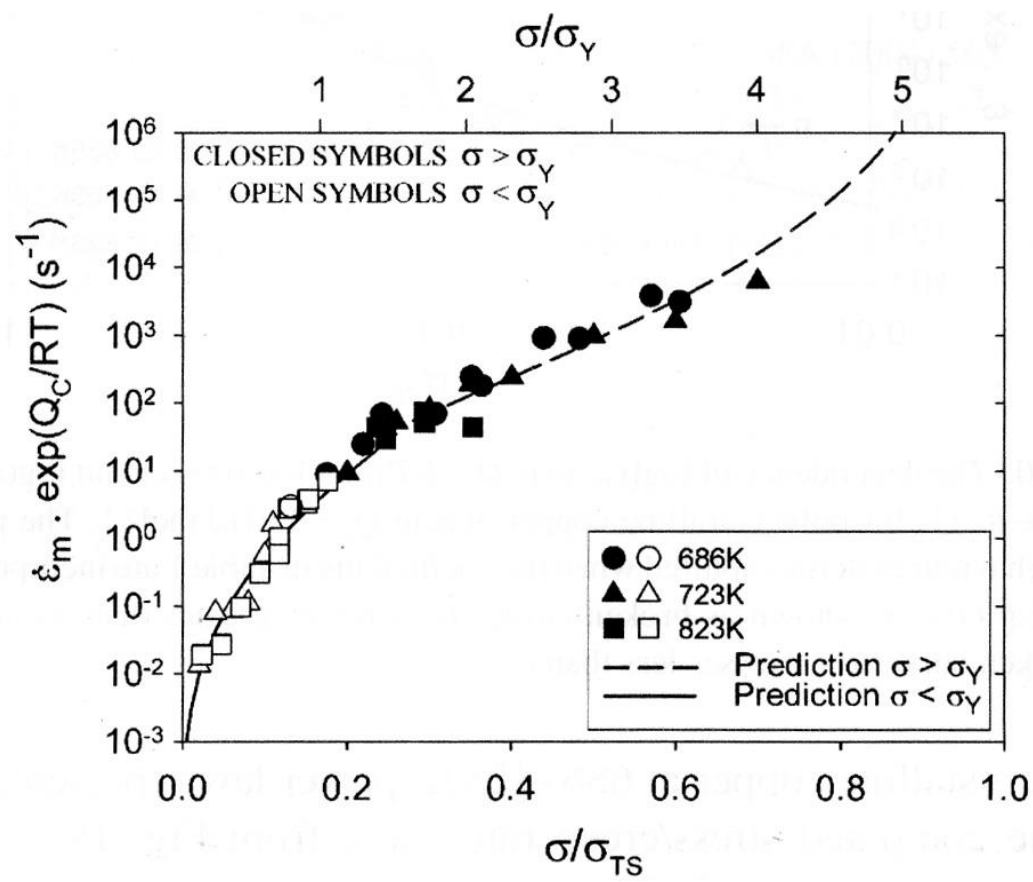

Figure 10. The dependencies of $\log \left[\dot{\varepsilon}_{m} \exp (110,000 / R T)\right]$ on $\left(\sigma / \sigma_{\mathrm{Y}}\right)$ and $\left(\sigma / \sigma_{\mathrm{TS}}\right)$ for polycrystalline copper (with $\mathrm{d} \cong 40 \mu \mathrm{m}$ ) at 686 to $823 \mathrm{~K}$. The behaviour patterns computed when the coefficients from Fig.9 are incorporated into eq. (9) are shown as a broken curve when $\sigma>\sigma_{\mathrm{Y}}$ and an unbroken curve when $\sigma<\sigma_{Y}$ [27]. 


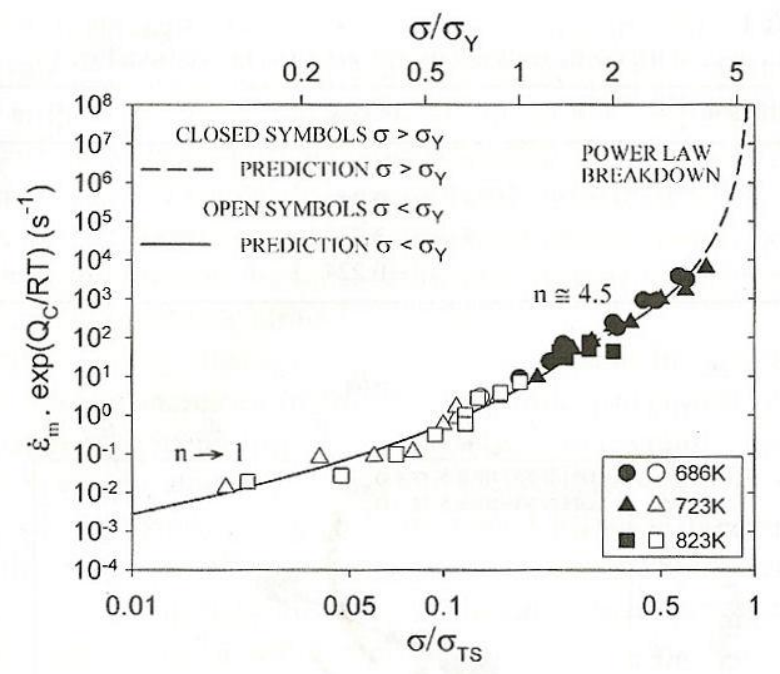

Figure 11. The dependencies of $\log \left[\dot{\varepsilon}_{m} \exp (110,000 / R T)\right]$ on $\log \left(\sigma / \sigma_{\mathrm{Y}}\right)$ and $\log \left(\sigma / \sigma_{\mathrm{TS}}\right)$ for polycrystalline copper (with $\mathrm{d} \cong 40 \mu \mathrm{m}$ ) at 686 to $823 \mathrm{~K}$. The power law patterns according to eq. (4), captured when the coefficients from Fig.9 are incorporated into eq. (3), are shown as a broken curve when $\sigma>\sigma_{Y}$ and an unbroken curve when $\sigma<\sigma_{Y}[27]$. 

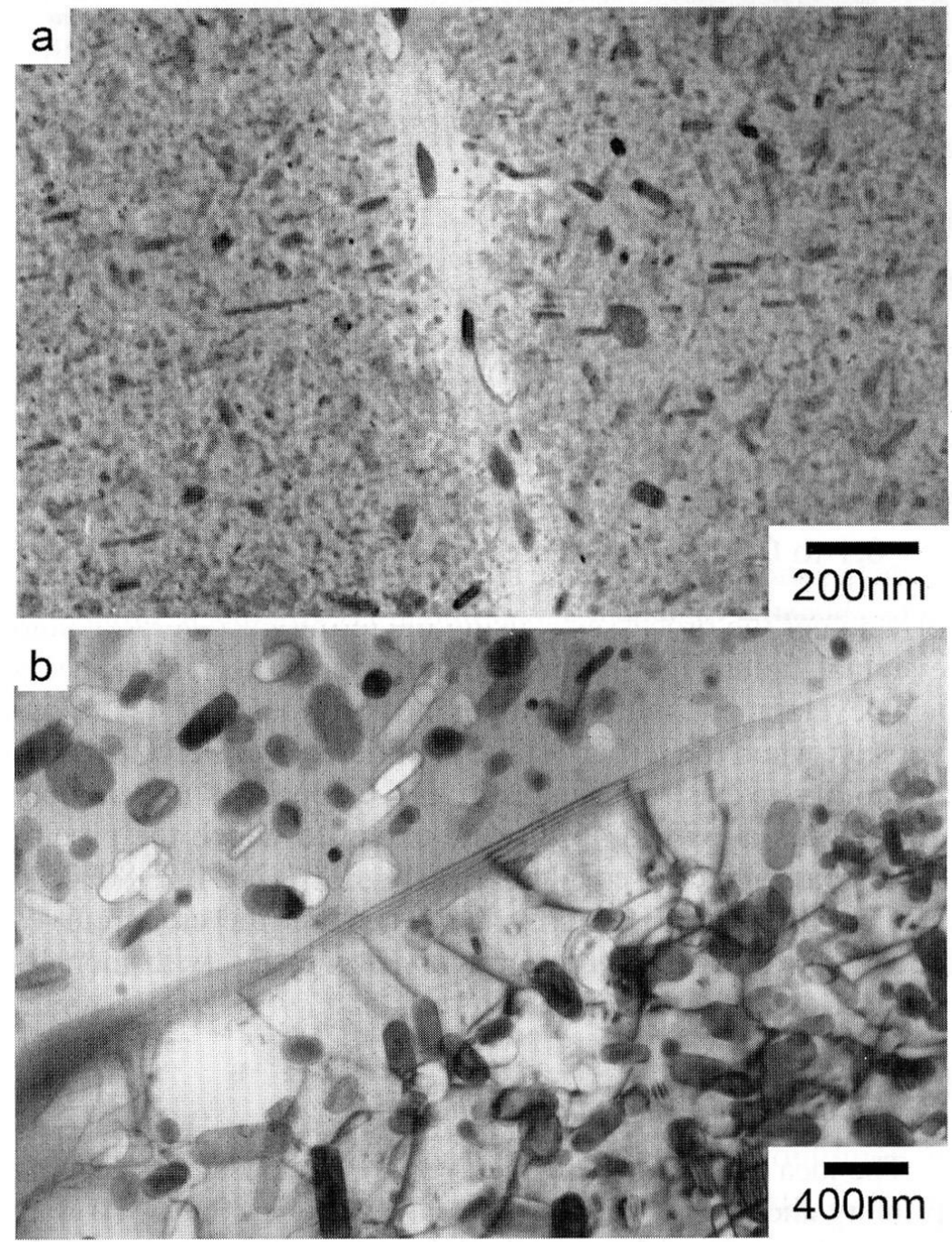

Figure 12. Transmission electron micrographs obtained for the aluminium alloy, 7010, (a) in the asheat-treated condition and (b) after 1915ks (532h) under a stress of $75 \mathrm{MPa}$ at $473 \mathrm{~K}$ [36]. 


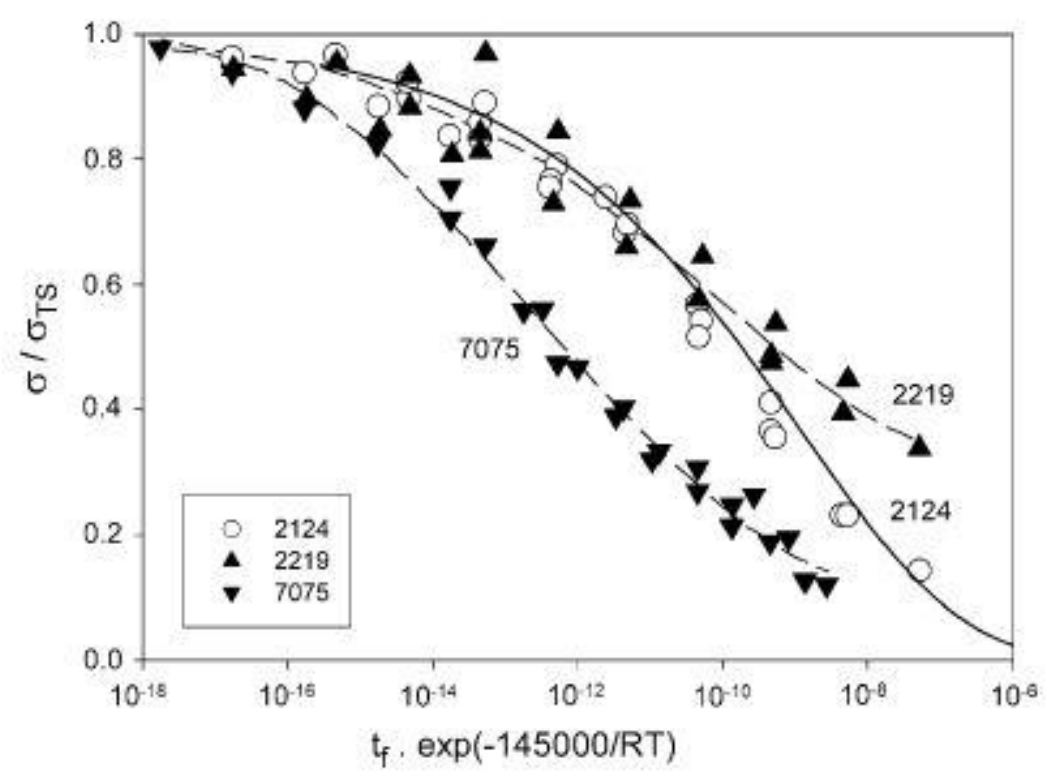

Figure 13. Sigmoidal master curves constructed [40] using eq. (2) to quantify stress rupture data recorded in long-term tests producing creep lives up to $100,000 \mathrm{~h}$ for the commercial aluminium alloys, 2124, 2219 and 7075 [43]. In the case of alloy 2124, the solid curve was predicted using eq. (2) to analyse results for $t_{\mathrm{f}}<1000 \mathrm{~h}[40]$. 